\title{
Can compassion be taught?
}

\author{
Gregory E Pence Department of Philosophy and School of Medicine, University of Alabama in Birmingham, USA
}

\section{Author's abstract}

Socrates (in the Meno) denied that virtues like courage could be taught, whereas Protagoras defended this claim. Compassion is discussed below in this context; it is distinguished from related, but different, moral qualities, and the role of imagination is emphasised. 'Sympathy' and role-modelling views of compassion's acquisition are criticised. Compassion can indeed be taught, but neither by the example of a few, isolated physicians nor by creation of Departments of Compassion. In replying to one standard objection to teaching compassion, it is emphasised that scientific competence and compassion aren't mutually exclusive.

Socrates and Protagoras long ago discussed whether virtues like courage and temperance could be taught (1). Suspicious of Sophists' claims to teach virtues for fees, Socrates argued that if virtues could be taught, teachers of virtues would be universally recognised. Protagoras countered powerfully that virtues could and indeed are taught by parents, friends, spouses, early childhood stories, and colleagues. Where Socrates appeared to argue that no one teaches virtues, Protagoras argued that everyone teaches them.

What about compassion in medical education? Can it be taught, suppressed or developed? If so, how? Or must we agree with Socrates' conclusion in the Meno that the presence of a virtue like compassion in any particular medical graduate is a 'gift of the gods'?

\section{The nature of compassion}

Whether compassion can be taught depends in part on what we take it to be. In defining compassion, it is important not to confuse it with related but different moral qualities. Like compassion, pity can be aroused by suffering, but may contain condescension and interpersonal distance absent in compassion. Benevolence and altruism carry much broader meanings than compassion and aren't focused on suffering. Concern for suffering in compassion is sometimes confused with concern for social justice, but these two qualities are logically and psychologically distinct. Compassion is

\section{Key words}

Compassion; sympathy; teaching ethics; medical ethics. characteristically focused on a particular person or situation, whereas concern for social justice may be very abstract, legalistic, and not involve any particular situation. Social justice characteristically involves problems of equality among humans, whereas compassion is not paradigmatically concerned with these problems and may even be focused on animals.

Imagination plays a key role in compassion in achieving understanding of, and feeling for, suffering people. This imagination involves self-transposal into another's situation. However, it is not enough merely to transpose one's own views unto the sufferer because 'selves' and personalities differ. Merely transposing one's own attitudes and beliefs unto the suffering person might be a grave mistake. (One is reminded here of George Bernard Shaw's quip: 'Do not do unto others what you want done to you: their tastes might be different.') Because people in fact differ greatly in what they value and feel, what creates suffering differs among people.

The imagination then of ideal compassion is more than imaginative self-transposal, more than the Golden Rule of putting oneself in another's place. A richer, more powerful imagination is needed to understand and feel the suffering of people of different backgrounds, values, and needs. Because of this gap between people, obtaining the imaginative understanding of suffering can at times be a worthy achievement like other medical achievements.

Part of the reason why this imaginative understanding is an achievement (and also why compassion differs from concern for social justice) is that this understanding presupposes an intimacy between people through which the sufferer reveals personal details to the listener. Such intimacy almost always is built on related moral qualities between listener and sufferer of trust, honesty, and the time and willingness to listen. Such intimacy and understanding is not a mundane, easilygenerated moral phenomenon, but is instead a 'virtue' as Aristotle understood the term: an excellence manifesting the best in humans and their civilisation.

\section{Criticism of standard views of teaching compassion}

In discussing views of teaching compassion, it is illuminating to consider the influential, eighteenth 
century view of sympathy described by David Hume and many others (2). These thinkers conceived of sympathy as an almost irresistible effect on an agent in encountering suffering. Taking the new Newtonian physics as their paradigm, these writers saw sympathetic concern as the effect of entering the 'field' of suffering, analogous to the action of a force field on a material object at a distance (3). Similarly with other strong emotions: one couldn't help but feel happy around joyous people, dampened by the depressed. Hence there was no need to teach compassion.

Today the eighteenth century view seems ludicrous. It fails to recognise the importance of internal beliefs and attitudes which make people receptive or indifferent to the 'force' of the suffering. It also puts responsibility for failures of compassion in the wrong place, as if the lack of compassion in a hospital could be because patients weren't suffering enough! (It may be true that some physicians need more of a 'stimulus' than others to 'pick up' suffering, but if this is true, it surely cannot be only the problem of the patient - as the eighteenth century view implies.)

This historical discussion is not without a point. Some medical educators claim that compassion is naturally 'picked up' by students in their medical training in interacting with suffering patients. The view seems to be that the primary goal of medical training is to produce scientifically competent physicians and, as for compassion, well, it will be picked up by 'osmosis' (perhaps 'perfusion' would be more exact). Notice how close this view is to the sympathy view. Both share the same theoretical defects and neither seems especially well-conceived.

With these problems in mind, consider now the most popular view of teaching compassion: the rolemodelling view. According to it, medical students become compassionate by observing senior physicians who treat patients with compassion. If compassion is to be taught, such physicians must 'model' compassion.

Although the role-modelling view is an improvement over the previous view, it is still infected with some of the same problems. Merely imitating compassionate behaviour is not compassion because real compassion stems from deeper, internal attitudes and emotions. Where compassionate behaviour is imitated in this way, it may be done as much to please and identify with the senior physician as much as because the suffering of the patient really matters.

Second, like the two previous views, the putative 'transfer' between senior physician and student is very murky and vague. Unless there is active and important discussion of why and how compassionate attitudes are expressed, the role-modelling view is in danger of degenerating into the previous view.

Must we then agree with Socrates that compassion in a medical graduate is a 'gift from the gods'? I think not. To see why is very important indeed.

\section{Protagoras was correct}

What Protagoras meant to emphasise was how an entire system, a social and professional network, develops moral ideals. Morality is not learned the way one learns to play a flute or to do a tracheotomy by observing a 'master' proficient in a certain craft or technique. Compassion similarly is not learned from a Master of Compassion (or the chief role-model thereof). Instead it is developed or not by the 'shape' of the medical environment in which students learn medicine. The overall medical context in which students thrive or stagnate is more important than the efforts (however noble) of any one individual.

Protagoras's view receives strong empirical support from two decades of research in social psychology built on Stanley Milgram's important research on obedience to (malevolent) authority (4). Many studies have replicated Milgram's results showing that normal individuals expressing deep concern for human welfare could be brought, by an authority figure in a relatively innocuous situation, to deliver potentially lethal shocks to innocent people ( 50 per cent in one experiment never stopped shocking their 'victims' at all, never disobeyed, continuously delivering $440+$ volts). The power of medical school is enormously more powerful than Milgram's lab in shaping behaviour, as are the penalties of disobedience. These findings can be extrapolated to medical environments: moral virtues like idealism, conscience, and inchoate compassion can easily be snuffed out by contradictory environments. Expectations and penalties of specific medical systems, rather than an individual's prior traits, best predict future behaviour.

For this reason, I believe the lay public and some admissions committees are mistaken in believing that selection of better 'input' to medical systems will produce more compassionate physicians. Compassion in undergraduates is notoriously difficult to discover or measure, especially in the brief, episodic encounters of mass education between professor and student where possible future requests for recommendations may lurk in a student's mind. But even if compassion could be accurately identified in undergraduates, the crucial problem remains of the great power of medical education to eradicate compassion.

\section{Changing the system to teach compassion}

The critical question which remains is how existing systems, which do not in reality reward compassion, might be changed so as at least not to undermine existing compassion in students and perhaps actively to support it.

The prior discussion of compassion argued that trust and intimacy are required for compassion to flourish. This implies two things are needed to support compassion: first, flexibility in the time-demands of students to allow them to pursue particular cases in which they become involved; second, systematic acceptance by medical teachers that such activities and the moral 
qualities they develop are worth encouraging.

Standard objections to these two requirements do not carry much weight. Some object that the student who 'holds a patient's hand' is not really as compassionate as he who forsakes the patient for the lab to develop a cure for the patient's disease. But, of course, many of the medical problems causing suffering today (for example, neoplasms, stroke, and kidney failure) are unlikely to be cured by a few hours in the lab, much less by beginning students. Compassion is often needed in precisely those medical conditions which are chronic, sometimes perhaps caused by unhealthy lifestyles, and for which the laboratory-orientated 'germ model' of disease seems inappropriate. Since medicine prides itself on adjusting treatment to changing knowledge of empirical facts, perhaps it is time to emphasise - constantly - to students that scientific medicine and compassion are not mutually exclusive.

In facing these facts and problems, great temptation exists to ignore the present thesis and to pursue mistaken solutions. The problem of how to teach compassion will not be solved by falling victim to the disease of Let's-Set-Up-A-Committee, nor will it be solved if compassion becomes a hot topic of after-dinner talks. Nor will the problem be solved in the way that some hospitals in the twentieth century have attempted to solve the social, financial, and familial problems of patients: by setting up a Department of Compassion. This device will only create a new bureaucracy and a new professional to attempt to solve a problem which (in truth) can only be solved between physicians, medical students, and patients. Historically, problems of compassion have come to be seen as problems of social workers, psychologists, hospital clergy, patient representatives, and (sometimes) psychiatrists. As a result, problems of compassion are increasingly seen not as the problems of minimally competent physicians but as problems of 'other' people.

It should be obvious then that the problem of teaching compassion is not going to be solved either by first and second-year courses in Human Values or Ethics. Although such courses are important in sustaining existing compassion in pre-clinical years by developing imaginative understanding through films, casestudies, and literature, their effects will almost certainly be destroyed if not reinforced by the crucially powerful settings of the subsequent years.
Making such changes is perhaps not as difficult as some might think, and the price of not making any changes is to give up the ideal of compassion in medicine (5). Important and profound changes in medical education can be made, given the will to do so by powerful professors therein. Compassion can indeed be taught if systems of medical education reward this virtue alongside other medical virtues such as diagnostic skill and factual command, but merely to rely on the efforts of a few individuals to transmit compassion however prestigious and tireless they may be - is to forsake compassion as a characteristic excellence of medical graduates. Without such systems to nurture it, compassion in any particular graduate remains a 'gift of the gods'. (6).

\section{References}

(1) Plato. Meno. Protagoras. In: Hamilton E, Cairns H, eds. Collected dialogues of Plato. Princeton, NJ: Princeton Univ Press, 1961.

(2) Hume D. A treatise of human nature. London, 1739; Oxford: Oxford University Press, 1978. Smith A. Theory of moral sentiments. London, 1759; Oxford: Oxford University Press, 1976. Hutcheson F. Inquiry into the original of our ideas of beauty and virtue. London, 1725; Amersham, Bucks: Avebury Publishing Co, Gregg International, 1969.

(3) Fiering N. Irresistible compassion: an aspect of eighteenth century sympathy and humanitarianism. Fournal of the history of ideas $1976 ; 36,2$ :

(4) Milgram S. Obedience to authority. New York: Harper \& Row, 1974; Baron R. Human aggression. London and New York: Plenum Press, 1977; Zimbardo P. A Pirandellian prison. New York Times magazine 1973, April.

(5) Pence G. Ethical options in medicine. Chapter 7: Relationships and virtues. Oradell, NJ: Medical Economics Books, 1980: 185-221.

(6) Marcia Angell, Kirk Avent, Carol Davis, William Goetter, and Max Michael contributed to this paper. Previous versions were read at the Philosophy and Medicine Symposium at New York University (1982), the Colloquium on Virtues and Moral Education at the University of South Carolina (1982), and at the 1982, Southeastern meeting of the Society for Health and Human Values at the Medical College of South Carolina in Charleston, SC. 